effect achieved with intrathecal methotrexate alone." Our observations agree with this statement, confirming the inadequacy of cranial irradiation alone and emphasising the efficacy of the spinal component of craniospinal radiation.

The length of meningeal remission after craniospinal irradiation, reaching from one to over three years in five patients, establishes this schedule as a practical means of treating first episodes of overt meningeal leukaemia. The median duration of 99 weeks unmaintained meningeal remission was a conservative estimate. This would have been the figure if all three of the children dying without meningeal relapse had lived to develop it before this point. Although the numbers of patients were small this remission was longer than the longest previously reported median remission of 67 weeks, ${ }^{1} 34$ weeks, ${ }^{3}$ and over 33 weeks ${ }^{5}$ (obtained with maintenance intrathecal methotrexate given every eight weeks during remission). Our results were obtained without the added imposition of repeated intrathecal injections and their associated symptomatic side effects during remission. Craniospinal irradiation (2400 rads) without prior clearing of the CSF blast cells by methotrexate produced long-term remissions extending for eight to 43 months in 13 out of 32 children, ${ }^{8}$ but about a third of these patients showed meningeal relapse after a median duration of nine months ( 39 weeks), which suggests that slightly better results may be obtained when craniospinal irradiation is given after remission induced with intrathecal methotrexate, even though the spinal dose of irradiation is lower (1000 rads in the present study). The lower spinal dose was used in an effort to avoid undue marrow and immunosuppression in children who had already been on systemic antileukaemic chemotherapy for one or more years and who were likely to remain on such treatment for a similar period. The subsequent survival of five patients for one to more than three years after completion of the craniospinal radiotherapy indicates that this dose of spinal radiotherapy did not unduly compromise subsequent systemic chemotherapy.

Serious encephalopathy ${ }^{10-12}$ was not encountered in this trial.
There might, however, be a hazard of radiation-induced brain damage in patients given a second course of CNS irradiation who have already had cranial irradiation as a component of CNS prophylaxis early in their disease. This commonly applies to patients currently presenting with their first episode of meningeal leukaemia. Several such patients are now receiving a second course of cranial plus spinal irradiation, so far without a report of serious complication. This question, as well as that of the efficacy of the treatment in patients who have already had CNS prophylaxis, will therefore be answered in time.

Finally, the findings of the present trial may be relevant to the design of improved initial "prophylactic" treatment of the CNS, since this is similarly directed at eliminating small numbers of leukaemic cells in the CNS. For instance, the addition of 1000 rads to the spine might give a lower rate of meningeal relapse than intrathecal methotrexate and cranial irradiation alone.

This trial was conducted by the Medical Research Council Working Party on Childhood Leukaemia.

\author{
References \\ ${ }^{1}$ Sullivan, M P, et al, Blood, 1971, 38, 680. \\ 2 Selawry, O S, and Odom, S, Proceedings of the American Association for \\ Cancer Research, 1968, 9, 62. \\ 3 Sullivan, M P, et al, Cancer, 1975, 35, 1066. \\ 4 Sullivan, M P, et al, Proceedings of the American Association for Cancer \\ Research, 1971, 12, 45. \\ ${ }^{5}$ Duttera, M J, et al, Lancet, 1973, 2, 703. \\ ${ }^{6}$ Hustu, H O, et al, Cancer, 1973, 32, 585. \\ ' Price, R A, and Johnson, W W, Cancer, 1973, 31, 520. \\ ${ }^{8}$ Huei-Mei Kuo, A, et al, Cancer, 1975, 36, 232. \\ - Cohen, L, in Biological Basis of Radiation Therapy, ed E E Schwartz. \\ Philadelphia, Lippincott, 1966. \\ ${ }^{10}$ Kay, H E M, et al, Archives of Disease in Childhood, 1972, 47, 344. \\ ${ }^{11}$ Rubinstein, L J, et al, Cancer, 1975, 35, 291. \\ 12 Price, R A, and Jamieson, P A, Cancer, 1975, 35, 306. \\ 13 Sullivan, M P, et al, Blood, 1969, 34, 301.
}

\title{
Bronchial reactivity to histamine before and after sodium cromoglycate in bronchial asthma
}

\author{
BANN KANG， ROBERT G TOWNLEY，C K LEE， BETTY MILLER KOLOTKIN
}

British Medical fournal, 1976, 1, 867-870

\begin{abstract}
Summary
Out of 19 patients with extrinsic bronchial asthma challenged with $123 \mu$ g histamine acid phosphate by intravenous infusion only 13 responded with a fall in FEV $_{1}$ of over $10 \%$ (mean $16 \%$ ). Seventeen of these patients were given histamine $2 \mathrm{mg} / \mathrm{ml}$ by aerosol, and all responded with a mean decrease in $F_{E V}$ of $37.8 \%$. When challenged with allergen extract by aerosol the mean decrease in $\mathrm{FEV}_{1}$ was $37.5 \%$. After $40 \mathrm{mg}$ sodium cromoglycate 15 of the 17 patients showed significant protection
\end{abstract}

\footnotetext{
Allergic Disease Centre and Department of Medicine, Creighton University School of Medicine, Omaha, Nebraska 68178

BANN KANG, MD, fellow in allergy and clinical immunology

ROBERT G TOWNLEY, MD, professor of medicine and microbiology $C \mathrm{~K}$ LEE, MD, fellow in allergy and clinical immunology

BETTY MILLER KOLOTKIN, MD, fellow in allergy and clinical immunology
}

against allergen challenge with a mean decrease in $\mathrm{FEV}_{1}$ of only $23 \cdot 6 \%$.

Inhalation of $40 \mathrm{mg}$ sodium cromoglycate, however, failed to protect against histamine given by either the intravenous or aerosol route. Histamine given intravenously to asthmatic patients produces less of a bronchial response than when given by aerosol, even though the intravenous route produces many more systemic symptoms, such as flushing and throbbing headache. The protection of sodium cromoglycate against an allergen inhalation challenge is not due to histamine antagonism.

\section{Introduction}

Sodium cromoglycate is an important and useful prophylactic drug in asthma. It inhibits immediate-type hypersensitivity reactions to antigen both in vitro and in vivo. ${ }^{12}$ In man the previous inhalation of sodium cromoglycate suppresses the immediate reaginic bronchial reaction to inhalation challenge with allergen. It also prevents the late (four to six hours) increase in airway obstruction in cases in which immediate and late reactions occur. ${ }^{2-5}$ 
The mode of action of sodium cromoglycate has been studied by many workers. We reported that protection against allergeninduced bronchoconstriction was significant at 30 minutes and five hours but not at 24 hours. Bronchial protection with sodium cromoglycate occurred during challenge with the same allergen given twice but not against a different allergen given five hours later, ${ }^{5}$ which suggests a mechanism of specific desensitisation of the bronchial mast cells. In a further study we assessed the effect of sodium cromoglycate on inhalation challenge with specific allergens as well as methacholine and histamine. ${ }^{6}$ The degree of decrease in forced vital capacity (FVC) and forced expiratory volume in one second $\left(\mathrm{FEV}_{1}\right)$ after allergen challenge was significantly reduced by sodium cromoglycaic in 15 of the 17 patients $(P<0.001)$. In the same patients sodium cromoglycate failed to show any significant difference from placebo in its effect on the bronchial response to histamine or methacholine. Kerr et $a l,{ }^{7}$ however, reported that sodium cromoglycate completely protected against the fall in $\mathrm{FVC}$ and $\mathrm{FEV}_{1}$ produced by an intravenous infusion of histamine.

The aim of the present study was to assess the protective effects of sodium cromoglycate in patients with asthma challenged with histamine given intravenously or by inhalation and with allergen given by inhalation.

\section{Patients and methods}

Nineteen patients were studied. Nine were male and 10 female, and their ages ranged from 14 to 54 (mean 29.5) years. All had longstanding bronchial asthma of moderate severity. All bronchodilators were stopped at least 12 hours and antihistamines 48 hours before the study. At the time of study no patient had any subjective symptoms of asthma. One was on prednisone $15 \mathrm{mg} /$ day. Baseline pulse rate and blood pressure were determined and the chest was examined for wheezing. FVC and FEV 1 were measured and the results used as indices of lung function. Symptoms and physical findings were recorded throughout.

After the baseline determinations each patient received by spinhaler either two $20-\mathrm{mg}$ capsules of sodium cromoglycate or two placebo capsules, treatment being allocated in a single-blind, randomised fashion. Thirty minutes later an intravenous infusion of histamine acidphosphate was begun at a rate of $12.3 \mu \mathrm{g}$ of the salt (equivalent to $4 \mu \mathrm{g}$ of the base) per minute for 10 minutes using a Harvard infusion pump. During the infusion spirometry was performed at five and 10 minutes, and blood pressure, heart rate, and any symptoms were recorded. Spirometry was again performed $5,10,15,20$, and 30 minutes after the infusion. Twenty-four hours later the experiment was repeated, the patients receiving the alternative compound.

Seventeen of the 19 patients were studied in a similar manner to determine the effects of sodium cromoglycate and placebo on the inhalation of histamine base $2 \mathrm{mg} / \mathrm{ml}$ by aerosol and an allergen extract. The specific allergen used was determined from the history and by skin tests. Altogether 7 patients were challenged with alternaria, 3 with ragweed, 1 with Russian thistle, 1 with burweed marsh elder, 2 with June grass, and 3 with house dust. The initial concentration used was 1000 protein nitrogen units $(\mathrm{PNU}) / \mathrm{ml}$. If less than a $20 \%$ decrease in $\mathrm{FEV}_{1}$ occurred a concentration of $10000 \mathrm{PNU} / \mathrm{ml}$ was used. Sodium cromoglycate, two $20-\mathrm{mg}$ capsules, and placebo were given by Spinhaler at random on alternate days 30 minutes before aerosol challenge with histamine acidphosphate, equivalent to $2 \mathrm{mg}$ of the base per $\mathrm{ml}$, or an allergen extract. The number of inhalations of histamine and allergen extract was increased sequentially at intervals of three and five minutes respectively in a sequence of $1,3,6,10,20$, and 40 inhalations. After each series of inhalations the $\mathrm{FEV}_{1}$ and FVC were determined, and if less than a $20 \%$ fall in $\mathrm{FEV}_{1}$ occurred the next series of inhalations was given. Histamine and allergen extract were administered by a Vaponefrin nebuliser activated by compressed air at a flow rate of $6 \mathrm{l} / \mathrm{min}$. Patients inhaled the aerosols to full inspiration. One inhalation delivered $20 \mathrm{~kg}$ histamine base.

Statistical evaluation of the results was carried out with the use of Student's $t$ test. Mean values are expressed \pm SE of mean.

\section{Results}

The average baseline values for $\mathrm{FEV}_{1}$ and FVC were $83 \%$ and $84 \%$ of the predicted values respectively. Neither sodium cromoglycate nor placebo induced any significant change in basal $\mathrm{FEV}_{1}$ or vital capacity. The mean baseline $\mathrm{FEV}_{1}$ was $3.03 \pm 0.191$, and after sodium cromoglycate and placebo it was $2.99 \pm 0.201$ and $3.07 \pm 0.201$ respectively.

After aerosol administration of histamine the $\mathrm{FEV}_{1}$ was reduced by $37.8 \pm 3.6 \%$ in those given placebo and by $35.5 \pm 3.3 \%$ in those given sodium cromoglycate. This difference was not significant. The average number of inhalations of histamine was 7 , with a range of 1 to 80 . Although all the patients had at least a $20 \%$ decrease in $\mathrm{FEV}_{1}$ after histamine aerosol none experienced headache, throbbing, flushing, nasal congestion, or sneezing. In contrast, after the intravenous administration of histamine all 19 patients experienced warmth, flushing, or throbbing, an obvious erythematous flushed appearance being apparent in the face and conjunctiva of most of them. In addition, in five patients nasal congestion, sneezing, and stuffiness of the nose occurred. Six patients complained of headache, in two of whom it was severe enough for them to wish not to have the test repeated. This accounts for the fact that there were 13 patients in the placebo group and only 11 in the sodium cromoglycate group who sustained a fall in $\mathrm{FEV}_{1}$ of $10 \%$ or more during the infusion (table I). No pronounced changes in pulse rate or blood pressure occurred after intravenous histamine. In 10 patients, however, the systolic blood pressure fell by $10 \mathrm{~mm} \mathrm{Hg}$, but in no case did this exceed $20 \mathrm{~mm} \mathrm{Hg}$.

Although all the patients showed a response to histamine inhalation with a fall in $\mathrm{FEV}_{1}$ of greater than $20 \%$, only 13 showed a response to intravenous infusion of histamine with a fall in $\mathrm{FEV}_{1}$ of more than $10 \%$ (table I). Baseline values of $\mathrm{FEV}_{1}$ and $\mathrm{FVC}$ were $80 \%$ of the predicted values. Within five minutes after the intravenous infusion of histamine was stopped the FEV 1 had returned to the baseline value in the sodium cromoglycate group and almost to the baseline value in the placebo group.

Fig 1 shows the percentage changes in $\mathrm{FEV}_{1}$ induced by intravenous histamine in the patients who had a $10 \%$ or more decrease in $\mathrm{FEV}_{1}$. Five minutes after the start of the infusion of histamine both the placebo and sodium cromoglycate groups had a decrease in FEV down to $84 \%$ of their baseline values. Within five minutes after stopping the infusion, however, the $\mathrm{FEV}_{1}$ in the sodium cromoglycate group had returned to $99 \%$ of the baseline value, whereas the $\mathrm{FEV}_{1}$ in the placebo group was only $92 \%$ of the baseline value. This difference was significant $(P<0.05)$.

The changes in FVC induced by intravenous histamine in the two groups were similar (fig 2), and, although the FVC 15 minutes after the infusion was greater in the sodium cromoglycate group, the differences were not statistically significant.

Table II shows the response to intravenous histamine in the six patients who responded with a $10 \%$ or less decrease in $\mathrm{FEV}_{1}$. Percentage decreases in $\mathrm{FEV}_{1}$ during the infusion did not differ significantly between the two treatment groups. After the infusion the FEV increased significantly above the baseline in the sodium cromoglycate group. Systemic symptoms induced by histamine were just as severe in these six patients as in the remaining patients. The mean age of this group was 36.6 years, or about 10 years older than the patients who did show bronchoconstriction when infused with histamine. The severity of asthma, as indicated by the amount of bronchodilation required and number and severity of attacks, was less in these six patients.

TABLE I-Mean changes in FEV ${ }_{1}$ and FVC (l) during and after intravenous infusion of histamine in 13 patients given placebo and 11 given sodium cromoglycate in whom the $F E V_{1}$ fell by more than $10 \%$ during the infusion. Results are expressed $\pm S E$ of mean

\begin{tabular}{|c|c|c|c|c|c|c|c|c|}
\hline & \multirow{2}{*}{ Baseline } & \multicolumn{2}{|c|}{ During infusion } & \multicolumn{5}{|c|}{ After infusion } \\
\hline & & $5 \mathrm{~min}$ & $10 \mathrm{~min}$ & $5 \mathrm{~min}$ & $10 \mathrm{~min}$ & $15 \mathrm{~min}$ & $20 \mathrm{~min}$ & $30 \mathrm{~min}$ \\
\hline $\begin{array}{l}\text { Placebo group } \\
(\mathrm{n}=13)\end{array} \quad\left\{\begin{array}{l}\mathrm{FEV}_{1} \\
\mathrm{FVC}^{\prime}\end{array}\right.$ & $\begin{array}{l}2.64 \pm 0.18 \\
3.55 \pm 0.18\end{array}$ & $\begin{array}{l}2 \cdot 23 \pm 0.17 \\
3 \cdot 28 \pm 0.19\end{array}$ & $\begin{array}{l}2 \cdot 19 \pm 0 \cdot 18 \\
3 \cdot 20 \pm 0 \cdot 20\end{array}$ & $\begin{array}{l}2.43 \pm 0.17 \\
3.44 \pm 0.18\end{array}$ & $\begin{array}{l}2 \cdot 44 \pm 0 \cdot 17 \\
3 \cdot 50 \pm 0.20\end{array}$ & $\begin{array}{l}2 \cdot 47 \pm 0.17 \\
3.50 \pm 0.19\end{array}$ & $\begin{array}{l}2.43 \pm 0.17 \\
3.44 \pm 0.18\end{array}$ & $\begin{array}{l}2.39 \pm 0.19 \\
3.44 \pm 0.21\end{array}$ \\
\hline $\begin{array}{c}\text { Sodium cromoglycate group } \\
(\mathbf{n}=\mathbf{1 1})\end{array}\left\{\begin{array}{l}\mathrm{FEV}_{1} \\
\text { FVC }^{2}\end{array}\right.$ & $\begin{array}{l}2.68 \pm 0.22 \\
3.62 \pm 0.19\end{array}$ & $\begin{array}{l}2 \cdot 26 \pm 0.25 \\
3 \cdot 22 \pm 0.21\end{array}$ & $\begin{array}{l}2.33 \pm 0.26 \\
3.25 \pm 0.20\end{array}$ & $\begin{array}{l}2 \cdot 66 \pm 0.23 \\
3.58 \pm 0.20\end{array}$ & $\begin{array}{l}2.67 \pm 0.22 \\
3.52 \pm 0.19\end{array}$ & $\begin{array}{l}2 \cdot 74 \pm 0.24 \\
3 \cdot 63 \pm 0.21\end{array}$ & $\begin{array}{l}2 \cdot 68 \pm 0.24 \\
3 \cdot 61 \pm 0.20\end{array}$ & $\begin{array}{l}2.67 \pm 0.24 \\
3.53 \pm 0.20\end{array}$ \\
\hline
\end{tabular}




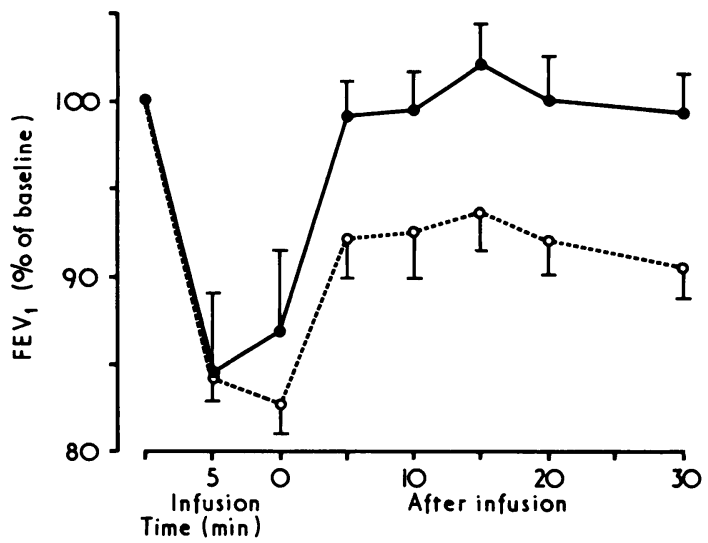

FIG 1-Percentage changes in $\mathrm{FEV}_{1}$ induced by intravenous histamine in patients with $10 \%$ or more decrease in $\mathrm{FEV}_{1}$. $\mathrm{O}=$ Placebo group. $=$ Sodium cromoglycate group. Results shown \pm SE of mean.

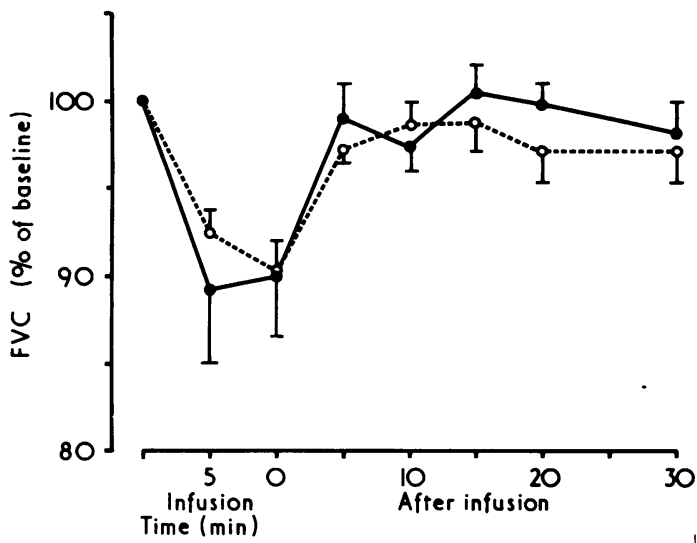

FIG 2-Percentage changes in FVC induced by intravenou histamine in patients with $10 \%$ or more decrease in FEV $\mathrm{O}=$ Placebo group. $=$ Sodium cromoglycate group. Results shown $\pm \mathrm{SE}$ of mean.

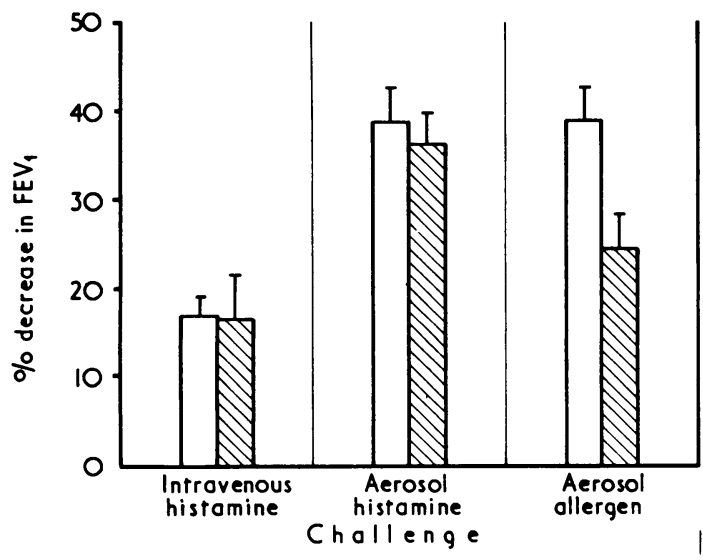

FIG 3-Percentage falls in FEV 1 after challenge with intravenous histamine, aerosol histamine, and allergen. Open symbols represent changes after placebo. Shaded symbols represent changes after sodium cromoglycate. Results shown $\pm \mathrm{SE}$ of mean.
Fig 3 shows the percentage falls in $\mathrm{FEV}_{1}$ after challenge with intravenous histamine, aerosol histamine, and aerosol allergen in these asthmatic patients. There was no significant difference in response to either intravenous or aerosol histamine between the sodium cromoglycate and placebo groups. Only 13 of the 19 patients responded to an intravenous infusion of histamine with a $10 \%$ or greater fall in $\mathrm{FEV}_{1}$, the mean decrease in these patients being only $16 \%$. In contrast, all the patients who received histamine by aerosol responded, the mean decreases in $\mathrm{FEV}_{1}$ being $37.8 \%$ after placebo and $35.5 \%$ after sodium cromoglycate. Again there was no protection with sodium cromoglycate. A significant degree of protection with sodium cromoglycate, however, occurred in 15 of the 17 patients after allergen challenge. After placebo and allergen challenge the mean decrease in $\mathrm{FEV}_{1}$ was $37.5 \pm 3.4 \%$, whereas after sodium cromoglycate the mean decrease was only $23.6 \pm 3.6 \%(P<0.01)$.

\section{Discussion}

This study was undertaken to further elucidate the action of sodium cromoglycate on the bronchoconstriction produced by histamine. Kerr et $a l^{7}$ reported that sodium cromoglycate completely inhibited the fall in vital capacity and $\mathrm{FEV}_{1}$ produced by intravenous infusion of histamine. They reported mean falls in FVC and FEV 1 of $20 \%$ and $28 \%$ respectively in 10 asthmatic patients after $50 \mu \mathrm{g}$ histamine hydrochloride given intravenously. After $40 \mathrm{mg}$ sodium cromoglycate they found no fall in vital capacity or $\mathrm{FEV}_{1}$ in response to histamine.

Ryo et $a l^{6}$ the following year found no protection with sodium cromoglycate against aerosol inhalation of histamine or methacholine in 17 asthmatics who showed marked protection against allergen inhalation challenges. We therefore attempted to study the effect of sodium cromoglycate in the manner that Kerr et al did on intravenously administered histamine in an effort to determine whether the action of sodium cromoglycate was different on intravenous versus aerosol histamine. The effect of histamine on smooth muscle may be produced by a direct action of the amine or by a delayed reflex action. ${ }^{8}$ Simonsson et al ${ }^{9}$ reported that the reflex action of histamine is mediated by vagal pathways and is only partially blocked by atropine.

Regardless of the mechanism of histamine bronchoconstriction we were unable to show any protection by sodium cromoglycate against histamine by either route of administration. We are unable to explain the difference between our results and those of Kerr et al. ${ }^{7}$ We found that the maximum effect of histamine occurred during the infusion period, the $\mathrm{FEV}_{1}$ returning almost to the baseline value within five minutes afterwards, whereas Kerr et al reported the maximum effect 20 minutes after the infusion. Possibly our patients had less severe asthma, since only 13 of the 19 showed more than a $10 \%$ fall in $\mathrm{FEV}_{1}$ with a mean of $16 \%$, whereas the patients of Kerr et al showed a $28 \%$ fall in $\mathrm{FEV}_{1}$. Nevertheless, all our patients responded to aerosol histamine with a mean decrease in $\mathrm{FEV}_{1}$ of $37 \%$. Bronchial sensitivity to histamine appears to be much greater when the aerosol route is used. The intravenous route resulted in systemic symptoms in all patients, with severe headache in two. The increased sensitivity by the aerosol route and lack of any other systemic effects makes it the preferable route of administration in attempting to assess bronchial sensitivity.

The increase in FEV 1 almost to the baseline value after histamine infusion and sodium cromoglycate and the increase to only $92 \%$ of the baseline value after histamine and placebo (fig 1) may be interpreted as showing a slight protective effect of

TABLE II-Mean changes in FEV 1 and FVC (l) during and after infusion of histamine in six patients given placebo and sodium cromoglycate in whom the $F E V_{1}$ fell by $10 \%$ or less. Results are expressed $\pm S E$ of mean

\begin{tabular}{|c|c|c|c|c|c|c|c|c|}
\hline & \multirow{2}{*}{ Baseline } & \multicolumn{2}{|c|}{ During infusion } & \multicolumn{5}{|c|}{ After infusion } \\
\hline & & $5 \mathrm{~min}$ & $10 \mathrm{~min}$ & $5 \mathrm{~min}$ & $10 \mathrm{~min}$ & $15 \mathrm{~min}$ & $20 \mathrm{~min}$ & $30 \mathrm{~min}$ \\
\hline Placebo group & $\begin{array}{l}2.78 \pm 0.47 \\
3.52 \pm 0.50\end{array}$ & $\begin{array}{l}2.76 \pm 0.49 \\
3.55 \pm 0.47\end{array}$ & $\begin{array}{l}2.65 \pm 0.46 \\
3.44 \pm 0.48\end{array}$ & $\begin{array}{l}2.79 \pm 0.46 \\
3.46 \pm 0.45\end{array}$ & $\begin{array}{l}2.80 \pm 0.49 \\
3.46 \pm 0.50\end{array}$ & $\begin{array}{l}3.04 \pm 0.50 \\
3.31 \pm 0.54\end{array}$ & $\begin{array}{l}3.04 \pm 0.49 \\
3.65 \pm 0.52\end{array}$ & $\begin{array}{l}2.78 \pm 0.47 \\
3.44 \pm 0.46\end{array}$ \\
\hline Sodium cromoglycate group $\left\{\begin{array}{l}\text { FEV }_{1} \\
\text { FVC }^{\prime}\end{array}\right.$ & $\begin{array}{l}2.57 \pm 0.54 \\
3.20 \pm 0.46\end{array}$ & $\begin{array}{l}2 \cdot 40 \pm 0 \cdot 59 \\
3 \cdot 16 \pm 0.54\end{array}$ & $\begin{array}{l}2.46 \pm 0.46 \\
3.15 \pm 0.61\end{array}$ & $\begin{array}{l}2.90 \pm 0.50 \\
3.47 \pm 0.54\end{array}$ & $\begin{array}{l}2.90 \pm 0.41 \\
3.43 \pm 0.41\end{array}$ & $\begin{array}{l}2.97 \pm 0.48 \\
3.58 \pm 0.56\end{array}$ & $\begin{array}{l}3.00 \pm 0.49 \\
3.62 \pm 0.56\end{array}$ & $\begin{array}{l}3.02 \pm 0.50 \\
3.67 \pm 0.53\end{array}$ \\
\hline
\end{tabular}


sodium cromoglycate. This effect was not due to a difference between the patients, since when we recalculated the results using the same 11 subjects for both placebo and sodium cromoglycate they were the same. Sodium cromoglycate has a slight phosphodiesterase inhibiting effect, which might explain the differences ${ }^{10}$; however, it has no effect on the histamine response of human bronchial smooth muscle. ${ }^{1}$ We have also shown that sodium cromoglycate has no effect on tracheal smooth-muscle contraction induced by histamine or methacholine. ${ }^{11}$ It does, however, inhibit allergen contraction of the passively sensitised human tracheal smooth muscles.

Our results of the lack of effect of sodium cromoglycate on histamine challenge are consistent with those of Pagelow. ${ }^{12} \mathrm{He}$ found no difference in the threshold of histamine bronchial reactivity with sodium cromoglycate or phentolamine. In

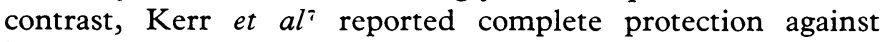
histamine with both these agents. We have studied the effect of sodium cromoglycate in vitro on the alpha-receptor contraction of isolated human trachea induced by adrenaline in the presence of propranolol. In this system we are unable to show any inhibition by sodium cromoglycate of alpha-receptor contraction. ${ }^{13}$

\section{References}

${ }^{1}$ Cox, J S G, Nature, 1967, 216, 1328

2 Altounyan, R E C, Acta Allergologica, 1967, 22, 487.

3 Pepys, J, et al, Lancet, 1968, 2, 134.

${ }^{4}$ Orie, N G M, et al, Disodium Cromoglycate in Allergic Airways Disease, ed J Pepys and A W Frankland, chap 4. London, Butterworth, 1970.

${ }^{5}$ Kolotkin, B M, Lee, C K, and Townley, R G, fournal of Allergy and Clinical Immunology, 1974, 53, 288.

${ }^{6}$ Ryo, U Y, Kang, B, and Townley, R G, fournal of Allergy, 1971, 47, 96.

${ }^{7}$ Kerr, J W, Govindaraj, M, and Patel, K R, British Medical fournal, 1970, 2, 139.

${ }^{8}$ De Kock, M A, et al, fournal of Applied Physiology, 1966, 21, 185.

9 Simonsson, B G, Jacobs, F M, and Nadel, J A, American Review of Respiratory Diseases, 1967, 95, 873.

${ }^{10}$ Lavin, N, Rachelefsky, G S, and Kaplan, S A, fournal of Allergy and Clinical Immunology, 1976, 57, 80.

11 Townley, R G, Acta Allergologica, 1974, 29, suppl No 11, p 15.

12 Pagelow, K O, Acta Allergologica, 1974, 29, 365.

13 Townley, R G, Advances in Asthma and Allergy, 1975, 2, No 3.

\title{
Fetal complications of obstetric cholestasis
}

\author{
RICHARD REID, K J IVEY, R H RENCORET, B STOREY
}

British Medical fournal, 1976, 1, 870-872

\section{Summary}

Among 56 pregnancies complicated by obstetric cholestasis five intrauterine deaths and one neonatal death occurred between 33 and 39 weeks, and a further six infants required urgent delivery for intrapartum asphyxia. Eighteen spontaneous premature deliveries occurred. Five mothers required specific treatment for unexplained postpartum haemorrhage. Cholestasis of pregnancy is therefore not a condition benign to the fetus, and it may contribute to increased maternal morbidity.

\section{Introduction}

The pattern of recurrent jaundice in late pregnancy has been shown by Svanborg ${ }^{1}$ and Thorling ${ }^{2}$ to be a clinical entity due to intrahepatic cholestasis. Kater and Mistilis $^{3}$ showed that pruritus of pregnancy is a less severe form of the same disorder. Obstetric cholestasis is generally accepted to be entirely benign with no ill effects on mother or child. ${ }^{4}{ }^{5}$ But our data, reported here, suggest that this belief cannot be substantiated.

\section{Patients and methods}

We reviewed the obstetric and paediatric records of all women confined in the obstetric section of Royal Prince Alfred Hospital

Departments of Obstetrics and Gynaecology, Paediatrics, and Gastroenterology, Royal Prince Alfred Hospital, Camperdown, NSW, 2050, Australia

RICHARD REID, MB, DOBST, registrar in obstetrics and gynaecology

K J IVEY, MD, MRCP, gastroenterologist and National Health and Medical Research Fellow

R H RENCORET, MD, MRCOG, clinical assistant in obstetrics and gynaecology

B STOREY, MB, MRACP, staff paediatrician
(King George V Memorial Hospital for Mothers and Babies) whose pregnancies were complicated by obstetric cholestasis in the 10 years from 1 January 1965 to 31 December 1974 . The criteria for the diagnosis of obstetric cholestasis were described by Kater and Mistilis in a survey at this hospital. ${ }^{3}$ Diagnosis based on clinical and biochemical findings was confirmed by liver biopsy in 11 patients.

Prematurity was judged by the clinical features of the newborn ${ }^{6}$ in conjunction with the obstetric estimate of gestation.

\section{Results}

The perinatal mortality rate in the 56 pregnancies reviewed was $11 \%$ and the incidence of premature delivery was $36 \%$. Five fetal deaths occurred among 40 multigravid women, in contrast to a single fetal death among the 16 primigravid patients.

The ethnic composition of the group of mothers who developed intrahepatic cholestasis is shown in table 1 . The proportion of patients with a Mediterranean ancestry was much greater than that of the overall population delivered at King George V Hospital.

TABLE I-Ethnic composition of group of mothers with cholestasis. Percentage of general hospital population that is formed by each ethnic group is shown for comparison

\begin{tabular}{|c|c|c|c|c|c|}
\hline & Greek & $\begin{array}{l}\text { Anglo- } \\
\text { Saxon }\end{array}$ & Italian & Yugoslav & Spanish \\
\hline $\begin{array}{l}\text { No }(1) \text { of patients } \\
\% \text { of hospital population }\end{array}$ & $\begin{array}{l}28(53) \\
22\end{array}$ & $\underset{41}{9(18)}$ & $\begin{array}{l}8(13) \\
6\end{array}$ & $14(10)$ & $4{ }_{3}^{4}(7)$ \\
\hline
\end{tabular}

For cultural and religious reasons, few of these women had used oral contraceptives, but a history of jaundice in association with these drugs was obtained from three women. Five other patients had previously had a cholecystectomy and another woman had had viral hepatitis five years before her pregnancy. Ten patients had $\beta$-thalassaemia minor, one had sickle cell trait, and another suffered from congenital spherocytosis.

Incidence of jaundice and pruritis-Twenty-nine pregnancies were complicated by jaundice and pruritus and 27 by pruritus alone. The gestational period at which symptoms began varied from 13 to 37 weeks (mean 30.5 weeks). The mean interval between the onset of symptoms and delivery was six and a half weeks and was the same 